\title{
PACTO PELO ENSINO MÉDIO E CURRÍCULO: REFLEXÕES A PARTIR DOS CADERNOS DE FORMAÇÃO E RELATÓRIO FINAL DO PNEM RONDÔNIA
}
M. O. Bertotti ${ }^{1 *}$; R. F. Simões ${ }^{2}$
1 Instituto Federal de Educação, Ciência e Tecnologia de Rondônia, 76870-000, Ariquemes-RO, Brasil
2 Universidade Federal de Rondônia, 76801-974, Porto Velho-RO, Brasil
*bertottimirian@gmail.com
Artigo submetido em 20/07/2016 e aceito em 30/08/2016

\section{RESUMO}
A vocação deste artigo é a de problematizar as dimensões do currículo do Ensino Médio existentes na formação continuada do governo federal intitulada "Pacto Nacional pelo Fortalecimento do Ensino Médio-PNEM", destinado aos docentes da rede de ensino estadual de Rondônia. Essa formação permitiu ver com outros olhos as ações pedagógicas dos professores com os sujeitos da última etapa da Educação Básica. Para tanto, se adota uma abordagem qualitativa, e seu percurso metodológico apoia-se nas análises dos cadernos da formação utilizados pelos cursistas e no relatório final elaborado pelo coordenador pedagógico do programa, no estado de
Rondônia. Mesmo estando a nossa pesquisa ainda em desenvolvimento, na fase de fundamentação teórica e coleta de dados, apoiamo-nos na teoria Multiculturalista, assim como na pedagogia de Freire, que traz à tona a leitura crítica, a problematização e a intervenção na realidade. Entendemos que as políticas de currículo são híbridas, polifônicas, produzidas por discursos que circulam em diferentes espaços-tempo educacionais. Compreendemos que o currículo como um instrumento social é construído coletivamente, com a participação de cada sujeito para fazer valer a qualidade da Educação nos territórios do Ensino Médio.

PALAVRAS-CHAVE: PNEM/Rondônia, currículo, educação.

\section{PACT FOR SECONDARY EDUCATION AND CURRICULUM: REFLECTIONS FROM FORMATION BOOKS AND FINAL REPORT OF PNEM RONDÔNIA}

\begin{abstract}
The vocation of this article is to discuss the dimensions of the existing secondary school curriculum in the continuing education of the federal government titled "Pacto Nacional pelo Fortalecimento do Ensino MédioPNEM" for the teachers of the state school system of Rondonia. This training allowed seeing with new eyes the pedagogical practices of teachers with the subject of the last stage of basic education. Therefore, it takes a qualitative approach, and its methodological approach relies on the analysis of the formation of the notebooks used by course participants and the final report prepared
\end{abstract}

by the educational program coordinator in the state of Rondônia. Even though our research still in development, the theoretical basis and data collection phase, we rely on the multiculturalist theory, as in Freire's pedagogy, which raises the critical reading, questioning and intervention in reality. We understand that curriculum policies are hybrid, polyphonic, produced by discourses that circulate in different educational space- time. We understand that the curriculum as a social instrument is built collectively, with the participation of each subject to enforce the quality of education in secondary school territories.

KEYWORDS: PNEM/Rondônia, curriculum, education. 


\section{INTRODUÇÃO}

Para estas duas vidas, um léxico só não é suficiente

Guimarães Rosa

Se refletirmos que o aprender a ensinar é um processo contínuo, acompanhando a vida profissional do educador, entenderemos que as experiências docentes não se esgotam na formação inicial; nesse sentido, os desafios dos programas de formação continuada almejam colocar em cena os debates que transitam nas ações pedagógicas diferenciadas, nos sujeitos estudantes, no desenvolvimento do currículo, nas estratégias e desafios na prática escolar; nessa acepção, Nóvoa (1995) sugere que a formação do professor deve estimular o desenvolvimento da visão crítica e reflexiva, que lhes forneça os meios de aprimoramento do pensamento e das suas práticas autônomas.

Assim, o Pacto Nacional pelo Fortalecimento do Ensino Médio entra em cena, no esforço em poder (re)desenhar as práticas pedagógicas dos professores na rede estadual do Ensino Médio de Rondônia, fazendo andar o carrossel dos sentidos para enriquecer o aprendizados com os seres humanos; Rubem Alves nos inspira sobre a Educação: "ensinar é um exercício de imortalidade. De alguma forma continuamos a viver com os olhos dos que aprenderam a ver o mundo a partir das nossas palavras".

Por seu turno, as reflexões de Candau (2000) nos ajudam a compreender que a formação continuada não pode ser concebida como um processo de acumulação (de cursos, palestras, seminários, etc., de conhecimentos ou técnicas), mas sim como um trabalho de reflexibilidade crítica sobre a prática de (re)construção permanente de uma identidade pessoal e profissional, em interação mútua.

Quando pensamos no conceito da palavra currículo, podemos nos aproximar da poesia de Guimarães Rosa, na epígrafe desse estudo; a poesia do autor envereda-nos pelas múltiplas acepções que permeiam o currículo; nesse sentido, percebemos que elas advêm das formas pelas quais a Educação é concebida, qual o seu papel e a sua importância na sociedade. A conceituação de currículo é tão complexa que sobre este tema Sacristán (2000) destaca: "não é estranho encontrar-se com perspectivas diversas que selecionam pontos de vista, aspectos parciais, enfoques alternativos com diferente amplitude". Por outro lado, os estudos sobre as políticas de currículo (Lopes, 2001) sublinham que há de se observar nas entrelinhas dos processos discursivos a legitimação de certos discursos em detrimento de outros, muitas vezes favorecida pela associação desses textos com matrizes de pensamento que circulam em diferentes grupos sociais e mesmo nos meios educacionais.

Olhando com outros olhos o campo do currículo no Brasil, não é difícil observar um hibridismo de discursos (Garcia, 1998). Num universo em que se percebe cada vez mais o multicultural, cuja "pluralidade de culturas, etnias, religiões, visões de mundo e outras dimensões das identidades infiltra-se, cada vez mais, nos diversos campos da vida contemporânea" (Moreira, 2001), há de se observar nos espaços de escolarização o Multiculturalismo (McLaren, 1997).Mas o que é mesmo o Multiculturalismo?

O debate entre a questão da diversidade, da alteridade e do papel assumido pela escola, em referência ao ensino num contexto multicultural, tem-se ampliado nos últimos anos em decorrência dos estudos relacionados à construção de um currículo e de uma linguagem que desmistifique visões eurocêntricas do conhecimento escolar. Embora se perceba uma crescente preocupação por parte das escolas brasileiras em reconhecer a multiplicidade de vozes e sujeitos presentes no espaço educativo, a prática pedagógica ainda permanece alicerçada em práticas de ensino que ocultam ou 
desvalorizam as condições de vida de grupos sociais minoritários e/ou marginalizados, tornando-se um espaço que para Santomé (2003) pode ser retratado como opressor, injusto e colonizador.

Para a maioria dos autores (Hall, 2006), o termo Multiculturalismo abarca diferentes definições e perspectivas que se contradizem. Por um lado, é um termo qualitativo; descreve as características sociais e os problemas de governabilidade apresentados por qualquer sociedade na qual diferentes comunidades culturais convivem e tentam construir uma vida em comum, ao mesmo tempo em que retêm algo de sua identidade original. Por outro lado, multiculturalismo é substantivo; refere-se às estratégias e políticas adotadas para governar ou administrar problemas de diversidade e multiplicidade gerados pelas sociedades multiculturais. É usualmente utilizado no singular, significando a filosofia específica ou a doutrina que sustenta as estratégias multiculturais.

Moreira (2001) sinaliza que é impossível pensar numa educação multicultural sem que nos questionemos sobre o professor e sua formação; é nesse sentido que a formação continuada entra em cena, num esforço em poder desenvolver nos docentes a capacidade de se (re)pensar os conhecimentos e as práticas legitimadas, provendo-os com "contradiscursos" (Lopes, 2001), possibilitando questionar as ações pedagógicas nas suas instituições de ensino, assim como refletir sobre as relações de poder existentes nesses universos curriculares.

Apesar de variadas acepções e perspectivas sobre o assunto, Sacristán (2000) assim o refletiu: "o currículo é uma práxis antes que um objeto estático emanado de um modelo coerente de pensar a educação ou as aprendizagens necessárias". Ora, entender a práxis como "um movimento operacionalizado simultaneamente pela ação e reflexão" (Ghedin, 2005) resulta o entendimento de que currículo não são apenas conteúdos programáticos, processos avaliativos e planos pedagógicos, ele pode ser tomado como um conjunto de processos e sujeitos, dessa forma a palavra de Moreira e Candau (2007) são complementos a este pensar,

(...) estamos entendendo currículo como as experiências escolares que se desdobram em torno do conhecimento, em meio a relações sociais, e que contribuem para a construção das identidades de nossos/as estudantes. Currículo associa-se, assim, ao conjunto de esforços pedagógicos desenvolvidos com intenções educativas. (MOREIRA; CANDAU, 2007, p.18)

O currículo pode ser compreendido como a concretização da função social da instituição escolar; aos educadores cabe a análise e as constantes discussões, de forma crítica e criativa, para torná-lo mais eficiente e atrativo. "O papel do educador no processo curricular é, assim, fundamental. Ele é um dos grandes artífices, queira ou não, da construção dos currículos que se materializam nas escolas e nas salas de aula" (Moreira; Candau, 2007)

Nesse contexto, tomamos o entendimento de que não há um currículo e sim currículos que contemplem a variedade, o pluralismo, as especificidades de cada instituição escolar. Partindo desse pressuposto e com o olhar direcionado ao Pacto pelo Fortalecimento do Ensino Médio- PNEM em Rondônia, optamos em trazer como objeto de estudo os cadernos de formação, assim como o relatório final procurando ver com outros olhos os desafios a serem enfrentados nesse processo formativo na região da Amazônia ocidental, mais especificamente no estado de Rondônia.

Devido ao recorte da pesquisa, neste momento, não se levantará questionamentos sobre os sentidos vinculados à formação Pacto pelo Ensino Médio e nem as Diretrizes Curriculares Nacionais para o Ensino Médio, as quais o programa relaciona-se, buscamos nos debruçar sobre os 
cadernos de estudos para os sujeitos do PNEM, assim como o relatório oficial dessa prática formativa.

\section{MATERIAIS E MÉTODO}

Direcionando nossos olhares aos cadernos da formação continuada Pacto pelo fortalecimento do Ensino Médio, especificamente àqueles que se voltavam a temática do currículo escolar e tomando também como objeto desta pesquisa o Relatório Final de PNEM Rondônia (2015), este estudo optou por uma abordagem qualitativa e adotou como procedimento técnico a pesquisa bibliográfica

A abordagem qualitativa permite que o pesquisador desvincule-se de dados quantificados podendo ser dedutiva, não se requer nem métodos, nem técnicas estatísticas, perpassa por aspectos subjetivos, possibilitando ao pesquisador atribuir sentidos e significados (Laville; Dionne, 1999).

Podemos considerar a pesquisa como exploratória, pois "visa proporcionar maior familiaridade com o problema com vistas a torná-lo explícito ou a construir hipóteses."(Gil, 2005, p. 21) Através da pesquisa bibliográfica (Marconi; Lakatos,1999), buscou-se referenciais teóricos já analisados e publicados em fontes variadas, no caso desta: a literatura já existente sobre a temática, as Diretrizes Curriculares Nacionais para o Ensino Médio - DCNEM, (BRASIL, 2012). A pesquisa documental também se fez necessária, por isso recorremos a fontes sem tratamento analítico, precipuamente ao Relatório Final do PNEM Rondônia (2015).

\section{RESULTADOS E DISCUSSÃO}

\subsection{PNEM: considerações gerais}

O Pacto pelo Ensino Médio foi uma ação do Ministério da Educação, instituído pela Portaria $\mathrm{n}^{\mathrm{o}} 1.140$ de 22 de novembro de 2013, em parceria com as universidades federais e governos estaduais. O Documento Orientador do Pacto Nacional pelo Ensino Médio anunciava os dados gerais do curso; nele é possível observarmos o perfil deste programa que abria portas para se pensar políticas de formação continuada para os professores da rede estadual brasileira:

Nome do Curso: Formação Continuada de Professores e Coordenadores Pedagógicos do Ensino Médio.

Área: Educação.

Subárea: Currículo.

Especialidade: Currículos específicos para níveis e tipos de educação.

Nível: Aperfeiçoamento.

Objetivo geral: Formar em nível de aperfeiçoamento todos os professores e coordenadores pedagógicos que atuam no Ensino Médio com vistas à valorização da formação do professor e dos profissionais da Educação a partir do diálogo entre conhecimentos teóricos e experiências docentes e de gestão pedagógica.

Descrição do Curso: O curso privilegia a articulação entre teoria e a prática no processo de formação docente, fundado no domínio de conhecimentos científicos e didáticos. Considera a escola como lócus de formação continuada e (re)construção coletiva do projeto político-pedagógico em suas 
articulações com as concepções de juventude e direito à qualidade social da educação. (BRASIL, 2014, p. 4, 5)

As ações do programa miraram colocar em cena os três seminários nacionais, coordenados pela Universidade Federal do Paraná; seminários estaduais e regionais, desenvolvidos pelas Secretarias de Educação para capacitar os formadores regionais e orientadores de estudo, ambos direcionados pelas Universidades Federais, em Rondônia, pela UNIR - Universidade Federal de Rondônia.

Em seguida, as formações aconteceram nas escolas, divididas em duas etapas, com atividades centradas no professor, ora individuais, como as leituras dos referencias teóricos e desenvolvimento de atividades relacionadas à temática na sua sala de aula; ora coletivas, quando em grupo apresentavam os registros e reflexões das atividades desenvolvidas e também discutiam acerca dos textos apresentados concatenando-os com o seu lócus de trabalho.

Na primeira etapa, com carga horária de 100 horas, o objetivo era compreender as Diretrizes Curriculares Nacionais do Ensino Médio, refletir coletivamente sobre a prática docente no Ensino Médio e a importância de ação coletiva na elaboração do Projeto Político Pedagógico da escola. Os subsídios teóricos discorriam sobre: os sujeitos do ensino médio e formação humana integral (caderno II); o ensino médio e formação humana integral (caderno I); o currículo do ensino médio, seus sujeitos e o desafio da formação humana integral (caderno III); a organização e gestão do trabalho pedagógico (caderno V); a avaliação no ensino médio (caderno VI); e as áreas de conhecimento e integração curricular (caderno IV).

A segunda etapa tinha como objetivo "Refletir sobre as áreas de conhecimento e as relações entre elas e seus componentes curriculares contextualizadas no Projeto Político Pedagógico da escola" (Doc. Orientador p.06). Os temas para discussões dos cadernos formadores eram: a organização do trabalho pedagógico no ensino médio (caderno I); Ciências Humanas - Sociologia, Filosofia, História e Geografia (caderno II); Ciências da natureza - Química, Física, Biologia (caderno III); Linguagens - Língua Portuguesa, Artes, Educação Física e Língua Estrangeira Moderna (caderno IV) e Matemática (caderno V).

Por uma fresta, é possível observar no universo das políticas de currículo que há investimentos em certas linhas e não em outras (Lopes, 2001); há a legitimação de certos discursos em detrimentos de outros, muitas vezes favorecida pela associação desses textos com matrizes de pensamento que circulam em diferentes grupos sociais e mesmo nos meios educacionais.

\subsection{Discussões curriculares na formação}

No debate sobre o (re)desenho curricular do Ensino Médio, o programa procurava instigar nos docentes e coordenadores as discussões sobre o currículo e a sua forma de (re)organização no caderno intitulado "O currículo do ensino médio, os seus sujeitos e o desafio da formação humana integral" (Brasil, 2013), abrindo portas para os subsídios teóricos que sustentavam as reflexões e permitiam a concretização dos pressupostos fornecidos pelo programa.

Com o intuito de aproximar os educadores das Diretrizes Curriculares Nacionais para o Ensino Médio (Brasil, 2012), o caderno de formação apresentava a necessidade de o currículo atender as expectativas de uma educação integral, associada as quatro dimensões: trabalho, cultura, ciência e tecnologia, já que é possível entender que a proposta curricular fragmentada não atende mais as expectativas dos sujeitos do ensino médio. 
(...) é possível verificar que a organização curricular do ensino médio que se instituiu ao longo do tempo se caracterizou pela fragmentação do conhecimento em disciplinas estanques e hierarquizadas, de modo a valorizar algumas áreas do conhecimento em detrimento de outras. Essa perspectiva curricular, no entanto, evidenciou seus limites, seja no que é praticado nas escolas, seja nos processos formativos dos novos professores. Entre as limitações, podemos sinalizar sua estruturação com base em um conjunto de saberes os quais nada ou pouco explicam, por serem dissociados da realidade vivida, experimentada. (BRASIL, 2013, p. 7a)

Além de propor a superação do caráter dualista, enciclopédico e descontextualizado que muitas vezes constituem o currículo, o caderno de formação III, da etapa I, apresenta o arranjo curricular da instituição escolar como resultado de uma construção coletiva e intencional: "não há neutralidade nesse processo e que todo o fazer pedagógico, do planejamento à avaliação, é um fazer político e é um processo eminentemente coletivo" (Brasil, 2013, p. 11). Compartilhando desse entendimento, encontramos nas palavras de Oliveira (2008) um complemento a essa acepção:

(...) é preciso se atentar para o fato de que o currículo não é neutro; ao ser veículo de conhecimentos selecionados, ele se liga ao poder, à homogeneização ou diferenciação da escola e por isso os educadores precisam estar alerta às suas implicações sociológicas e culturais quando de sua estruturação. (OLIVEIRA, 2008, p.545)

Os estudos de Ramos (2011) problematizam as propostas curriculares para o Ensino Médio nas quais o trabalho, as dimensões da formação humana e a cidadania são elementos constitutivos nos territórios da última etapa da Educação Básica. Mas as Diretrizes Curriculares Nacionais foram claras ao recomendarem a organização dos conteúdos de ensino em estudos ou áreas interdisciplinares e projetos. Nesse sentido, implicaria, também, "(re)significar os conteúdos curriculares como meios para constituição de competências e valores, e não como objetivos do ensino em si mesmos" (Brasil, 1998, p. 37). Como componentes curriculares, então, teríamos um conjunto contextualizado de situações voltadas para a geração de competências. Nesse sentido, os métodos assumiram papel relevante nessas orientações.

A formação trouxe a baila às dimensões explicativas e prescritivas do currículo: uma faz com que compreendamos o que, como e por que organizamos o currículo; a outra nos remete à necessidade de definirmos pontos de chegada e as trajetórias que tomaremos. O currículo não é uma organização imparcial, técnica, é uma construção política da instituição escolar com reflexos diretos em todos os envolvidos, norteador das ações pedagógicas, do trabalho docente, é o currículo "o coração da escola", como denominaram Moreira e Candau (2007).

O PNEM, através do caderno III da primeira etapa, também pôs em discussão a importância do reconhecimento dos sujeitos do ensino médio, que vêm constituídos de discursos, linguagens e vivências singulares, e que muitas vezes não têm suas expectativas contempladas pela instituição escolar, fez o chamamento para que se atenda à diversidade juvenil do Ensino Médio; entretanto ressalta a importância de se assegurar uma formação integradora entre as concepções do trabalho, ciência, tecnologia e cultura.

Quando se traz para o debate o Trabalho, Ciência, Tecnologia e Cultura, as reflexões de Ramos (2011) sublinham que são dimensões da vida humana, devendo, portanto, serem integradas ao currículo, tendo o trabalho como princípio educativo, implicando referir-se a uma formação baseada no processo histórico e ontológico de produção da existência humana. No entanto, há de se 
lembrar que a produção humana se realiza sob as condições sociais e históricas determinadas pelas relações sociais.

A integração das áreas de conhecimentos e do currículo também é posta em evidência na formação docente no caderno IV da primeira etapa. O caderno de formação define as áreas de conhecimento como um conjunto de conhecimentos que podem referenciar um objeto comum, destacando assim a importância do entrelaçamento do saber. Não estaríamos sendo audaciosos se agregássemos Morin (2011) quando se refere à conjugação dos saberes às discussões proposta pela formação, quando a mesma ressalta

(...) as áreas de conhecimento na organização curricular, portanto, devem expressar o potencial de aglutinação, integração e interlocução de campos de saber, ampliando o diálogo entre os componentes curriculares e seus respectivos professores, com consequências perceptíveis pelos educandos e transformadoras da cultura escolar rígida e fragmentada. (BRASIL, 2013, p.15b)

A formação continuada reitera a necessidade de trabalhos interdisciplinares e coletivos, visto que todas as ações do ambiente escolar convergem em um único objetivo: a formação do aluno. Entretanto ratifica a necessidade das especificidades dos componentes curriculares; desta forma, entendemos que a visão geral, contextualizada do objeto, não deve suprimir a visão particular que cada componente curricular pode atribuir; ambas devem complementar-se.

Quando nos aproximamos da discussão sobre a interdisciplinaridade como método, Ramos (2011) nos ajuda a compreender que é uma reconstituição da totalidade pela relação entre os conceitos originados a partir de distintos recortes da realidade; isto é, isso tem como objetivo possibilitar a compreensão do significado dos conceitos, das razões e dos métodos pelos quais se pode conhecer o real e apropriá-lo em seu potencial para o ser humano.

Por sua vez, Frigotto (1995) reflete sobre a necessidade do trabalho interdisciplinar;

O trabalho interdisciplinar se apresenta como uma necessidade imperativa pela simples razão de que a parte que isolamos ou arrancamos do contexto originário do real para poder ser explicada efetivamente, isto é, revelar no plano do pensamento e do conhecimento as determinações que assim a constituem, enquanto parte, tem que ser explicitada na integridade das características e qualidades da totalidade. (FRIGOTTO, 1995, p. 33)

Os cadernos de formação enfatizaram a necessidade de um arranjo curricular que prime pela interdisciplinaridade, não devendo apenas conectar os conhecimentos, mas contextualizá-los. O contexto é aqui entendido como ir além de situar de conhecimento com as práticas sociais; seria uma estratégia para análise da realidade que toma como base o conhecimento sistematizado e tem como ponto de partida o concreto. Nas palavras de Domingues, Toschi e Oliveira (2000) "Por meio da contextualização seria possível relacionar disciplinas com o cotidiano dos alunos, com a realidade das escolas, com as características locais e regionais."

Frisando a importância do contexto na elaboração da proposta curricular, ora representada pela (re)escrita o Projeto Pedagógico da instituição, no caderno Áreas de conhecimento e integração curricular (Brasil, 2013b), o programa de formação sugeriu uma proposta de currículo apoiada no método de ensino da pedagogia histórico crítica. Segundo Steimbach (s.d) foi na obra de João Luiz Gasparin (2007) intitulada "Uma didática para a pedagogia histórico-crítica" que cinco etapas para 
uma metodologia na perspectiva histórico crítica foram elencadas. A saber: a) prática social; b) problematização; c) instrumentalização d) catarse; e) prática social.

Nesse contexto, toma-se como princípio básico, a prática social inicial; ela seria o ponto de partida para o processo pedagógico partir das vivências do educando estabelecendo vínculos com a realidade, considerando o global, o contexto. A problematização é o momento de discussão dos conteúdos: "Um conteúdo problematizado deverá mostrar-se através de dimensões várias: conceitual, histórica, social,política, estética, religiosa etc. (Steimbach, s/d, p.03) A instrumentalização seria a apropriação dos conhecimentos culturais e científicos para melhorar os conceitos primários sobre o assunto.. A catarse seria a incorporação, assimilação dos instrumentos. Por fim, a prática social seria a mudança social advinda de uma mudança individual quando através de ações demonstra-se que o conteúdo foi absorvido e compreendido.

É importante ressaltar que mesmo apresentando uma proposta metodológica apoiado na pedagogia histórico crítica, o programa não descartou outras possibilidades de arranjos ou processos metodológicos, desde que busquem uma perspectiva interdisciplinar, que percebam o conhecimento como transformador de realidades individuais e coletivas, o que nos aproxima do relatório final encaminhado para o Ministério da Educação.

Há de se destacar nas palavras desse texto, o esforço em se poder compartilhar saberes, diálogos, força de vontade, enfim, práticas formativas que procuraram levar em conta os potenciais dos sujeitos;

(...) registram-se os passos rumo à execução desse projeto cujo objetivo é repensar a ação pedagógica dos professores, compartilhando iniciativas, trabalho em equipes, diálogos, força de vontade, dedicação, compromisso, responsabilidade, compreensão, flexibilidade, o que possibilitou abrir portas para a criação de novas redes de sociabilidade com os recursos tecnológicos presentes também na vida escolar. (UNIR, 2015, p. 6)

Vale observar o protagonismo desses sujeitos nas formações; além dos encontros, (re)ssignificando, portanto, a questão dos territórios geográficos distantes no estado de Rondônia, foi criado um espaço nas redes de sociabilidade, na tentativa de se poder compartilhar a formação dos docentes.

O relatório final também destaca a participação dos professores, que foram orientados a produzir textos a partir das leituras e fontes levantadas, tendo como horizonte as questões problematizadas no âmbito da pesquisa;

(...) a formação dos Formadores Regionais no estado de Rondônia contou com a participação efetiva de todos os professores e equipe gestora; foi realizada com êxito, buscando apresentar um conjunto de temas fundamentados nas DCNEM, para subsidiar a formação continuada dos professores. Um dos objetivos foi possibilitar a compreensão das diretrizes curriculares nacionais, criando-se um espaço para a reflexão coletiva sobre a prática docente e a importância da participação de todos os atores do processo educativo, numa tentativa de reescrever o Projeto Político Pedagógico da escola- PPP. (UNIR, 2015, p. 8) 
Os registros anunciam um pacto dos professores da rede estadual de ensino no estado de Rondônia com o compromisso e a participação neste projeto formativo, deixando entrever, portanto, que os sujeitos participaram significativamente como mediadores entre os diferentes contextos de produção; nesse sentido, refletimos que essas associações também envolvem perspectivas pedagógicas diversas, aproximando-nos das reflexões de Freire, que traz à tona a leitura crítica, a problematização e a intervenção na realidade.

\section{CONCLUSÃO}

A partir da leitura e análise dos cadernos de formação do PNEM, que voltavam-se à temática do currículo escolar, do entrelaçamento com o Relatório final, produzido pela Universidade de Rondônia e com a bibliografia selecionada, percebe-se que o material da formação continuada cumpre seu objetivo ao propiciar subsídios teóricos que nortearam discussões e debates sobre outras abordagens e possibilidades de arranjos curriculares para atender as expectativas dos sujeitos da última etapa da educação básica. Ter como lócus da formação escolar a sua própria instituição pressupõe que os educadores sintam-se parte do processo de (re)escrita do Projeto Pedagógico da instituição, tendo voz e vez.

Entre os desafios de todos nós educadores está a necessidade de alimentar novas esperanças e novos paradigmas no âmbito educacional. Mas quem disse que não há lacunas? Quem sabe, o poeta Fernando Pessoa possa nos ajudar e (re)pensar estes caminhos insólitos e invisíveis nos territórios da Educação: "Há um tempo em que é preciso abandonar as roupas usadas, que já tem a forma do nosso corpo, e esquecer os nossos caminhos que nos levam sempre aos mesmos lugares. É o tempo da travessia: e, se não ousarmos fazê-la, teremos ficado, para sempre, à margem de nós mesmos".

Assim, esse estudo procurou aprofundar as análises dos cadernos de formação à luz de outras fontes teóricas, refletiu sobre a relação entre teoria e prática a que se propôs o programa, no esforço em contribuir para a análise e a formulação de políticas pedagógicas em Rondônia, a partir da exposição da problemática e de perspectivas de enfrentamento, tendo o trabalho escolar como uma das dimensões fundamentais da formação intelectual e cultural dos trabalhadores; em certa medida, uma tentativa de compreendermos o currículo como um instrumento social, construído coletivamente, com a participação de cada sujeito para fazer valer a qualidade da Educação nos territórios do Ensino Médio brasileiro.

\section{REFERÊNCIAS}

BRASIL. Documento orientador das ações de formação continuada de professores e coordenadores pedagógicos do Ensino Médio em 2014. Brasília, MEC/SEB, 2014. Disponível em:

< http://pactoensinomedio.mec.gov.br/images/pdf/documento_orientador.pdf>. Último acesso; 19/07/16

BRASIL. MEC. Secretaria de Educação Básica. Formação de professores do ensino médio, etapa I - caderno III: o currículo do ensino médio, seu sujeito e o desafio da formação humana integral. Curitiba: UFPR/Setor de Educação, 2013a.

BRASIL. Secretaria de Educação Básica. Formação de professores do ensino médio, etapa I - caderno IV: áreas de conhecimento e integração curricular / Ministério da Educação, Secretaria de Educação Básica- Curitiba: UFPR/Setor de Educação, 2013b.

CANDAU, V. M. F. (Org.) Rumo a uma nova Didática. Petrópolis, RJ: Vozes, 2000.

DOMINGUES, José Juiz; TOSCHI, Nirza Seabra; OLIVEIRA, João Ferreira de. A reforma do Ensino Médio: A nova formulação curricular e a realidade da escola pública. Educação \& Sociedade, ano XXI, nº 70, Abril/00 
FRIGOTTO. G. A interdisciplinaridade como necessidade e como problema nas Ciências Sociais. In: JANTSCH, A. P.; BIANCHETTI, L. (Org.). A interdisciplinaridade: para além da filosofia do sujeito. Petrópolis: Vozes, 1995. p. 25-49.

GARCÍA, N. C. Culturas híbridas: estratégias para entrar e sair da modernidade. São Paulo: Edusp, 1998.

GIL, Antonio Carlos. Como elaborar projetos de pesquisa. São Paulo: Atlas, 1991.

GHEDIN, Evandro. Professor reflexivo: da alienação da técnica à autonomia da crítica. In: PIMENTA, Selam Garrido; GHEDIN, Evandro (orgs). Professor reflexivo no Brasil: gênese e crítica de um conceito. 3 ed. São Paulo: Cortez, 2005.

HALL, S. Da diáspora: identidades e mediações culturais. Belo Horizonte: Editora UFMG, 2006.

LAVILLE, Christian; DIONNE, Jean. A construção do saber: manual de metodologia de pesquisa em ciências humanas. Porto Alegre: Artes Médicas; Belo Horizonte: Ed. da UFMG, 1999.

LOPES, A. C. Competências na organização curricular da reforma do Ensino Médio. Boletim Técnico do Senac, Rio de Janeiro, v. 27, n. 3, p. 1-20, 2001.

MARCONI, Marina de Andrade; LAKATOS, Eva Maria. Técnicas de pesquisa. São Paulo: Atlas, 1999.

MCLAREN, P. Multiculturalismo Crítico. São Paulo: Cortez, 1997.

MOREIRA, A. F. B. (2001). Currículo, cultura e formação de professores. Revista Educar, Curitiba, Editora da UFPR, n. 17, p. 39-52

MOREIRA, Antônio Flávio Barbosa; CANDAU, Vera Maria. Indagações sobre o currículo: currículo, conhecimento e cultura. Brasília: Ministério da Educação, 2007, p. 5 - 21

NÓVOA, A. (Org). Os professores e a sua formação. Lisboa: Instituto de Inovação Educacional, 1995.

OLIVEIRA, Zélia Maria Freire de.CURRÍCULO: um instrumento educacional, social e cultural. Rev. Diálogo Educ., Curitiba, v. 8, n. 24, p. 535-548, maio/ago. 2008

RAMOS, M. N. Educação profissional história e legislação. Curitiba, PR. Instituto Federal do Paraná, 2011.

SACRISTÁN, José Gimeno. O currículo: uma reflexão sobre a prática. Porto Alegre: Artmed, 2000.

SANTOMÉ, J. T. A educação em tempos de neoliberalismo. Porto Alegre: Artmed, 2003.

SILVA, Edna Lúcia da. Metodologia da pesquisa e elaboração de dissertação. - 4. ed. rev. atual.- Florianópolis: UFSC, 2005. 138p.

STEIMBACH, Allan Andrei. O processo de ensino numa perspectiva histórico-crítica. Disponível em:<http://famper.com.br/download/allan.pdf>. Acesso em: 13/07/2016.

UNIR. Relatório final do PNEM/RO-2014-2015. Porto Velho. UNIR/COORDENADORIA DE CULTURA E EXTENSÃO - CCE. 2015. 